\title{
Antitumor Hybrid BT009K Modulates Inflammation Induced Neovascuaralization in Both Tumorigenic and Non-Tumorigenic Model System
}

\author{
Shamanth Neralagundi H.G. ${ }^{1}$, Zabiulla ${ }^{2}$, Shaukath Ara Khanum ${ }^{2}$, Manjunatha H. ${ }^{3}$, Prabhakar B.T. ${ }^{*}$ \\ ${ }^{1}$ Molecular Biomedicine Laboratory, Postgraduate Department of Studies and Research in Biotechnology, Sahyadri Science College (Autonomous), \\ Kuvempu University, Shivamogga, Karnataka 577203, India. \\ ${ }^{2}$ Department of Chemistry, Yuvaraja's College, University of Mysore, Mysore 570005, Karnataka, India. \\ ${ }^{3}$ Department of PG studies and Research in Biotechnology, Jnana Sahyadri Shankargahtta, Shivamogga, Karnataka 577203, India.
}

\begin{tabular}{|c|c|}
\hline ARTICLE INFO & ABSTRACT \\
\hline & \multirow{8}{*}{$\begin{array}{l}\text { Cancer being one of the most dreadful diseases and inflammation in cancer is one of the emerged Hallmarks of cancer. } \\
\text { Discovering new drugs with minimal side effects plays a vital role in drug development process for the treatment of } \\
\text { cancer. As an approach antitumor hybrid of "Benzophenone coupled with diamide analog "BT009K" or N-(2-\{2- } \\
\text { [4-(4-bromo-benzoyl)-2-methyl-phenoxy]-acetylamino }\} \text {-phenyl)-2-[2-methyl-4-(2-methyl-benzoyl)-phenoxy] was } \\
\text { screened against different cell lines. Cytotoxic effect was found to be effective against EAC with prolonged effect. The } \\
\text { in-vivo antitumor effect was observed in EAC ascites tumor model system with reduced peritoneal neovascularisation. } \\
\text { Further histological examination with endothelial marker CD31 confirmed the angioregressive effect of BT009K. } \\
\text { The results were additionally confirmed in a non-tumorigenic model like CAM and rat corneal angiogenesis assay } \\
\text { indicating reduced microvessel density count by BT009K. Further BT009K induces the anti-invasive effect in EAC } \\
\text { cells in-vitro which could be further developed into therapeutic potential. }\end{array}$} \\
\hline $01 / 2018$ & \\
\hline Acce & \\
\hline Available online: $29 / 04 / 2018$ & \\
\hline & \\
\hline & \\
\hline Inflammation, angiogenesis, & \\
\hline & \\
\hline
\end{tabular}

\section{INTRODUCTION}

Cancer is defined as the interplay between cell intrinsic and extrinsic process due to the instability in the genome, abnormality in the proliferation of cells, inaccuracy in the stromal environment and atypical differentiation amongst epithelial and mesenchymal status (Eran et al., 2013). The development of cancer can be attributed with six vital possessions that cells undergo evasion of apoptosis, uncontrolled angiogenesis, negligence to anti-proliferative signals, unconstrained replicative potential, tissue invasion followed by metastasis (Hanahan and Weinberg, 2000). Three phases take place in the development of cancer initiation, promotion, and progression. Initiation is started

\footnotetext{
${ }^{*}$ Corresponding Author

Dr. Prabhakar B.T, Assistant Professor, Molecular Biomedicine

Laboratory, Postgraduate Department of Studies and Research in Biotechnology, Sahyadri Science College, Kuvempu University, Karnataka 577203, India.E-mail:Prabhakarbt1@ kussc.org
}

through genomic instability in cancer cells promoting for tumor development endorsed by the survival and clonal expansion and followed by significant growth in tumor size and metastasis of tumor cells (Kinzler and Vogelstein, 1996).

Inflammation, the physiological reaction of the body due to the mutilation of tissue damage instigated through microbes, wounds, chemical irritation (Philip et al., 2004). Inflammation categorized into acute and chronic if the healing of inflammation does not take place it progress from acute to chronic inflammation resulting in recruitment of lymphocytes, leukocytes and various inflammatory cells at the site of the inflamed site. Further chronic inflammation mediates to the formation of the tumor by making a suitable environment for the cancer cells (Coussens and Werb, 2002; Nathan, 2002). Inflammation during tumor progression induces the angiogenic mediators triggering the angiogenesis (Pollard JW, 2006). Angiogenesis is known as restoration and progression of the new vascular system from the existing matured vasculature to form branching network (Carmeliet, 2005). 
Extensive angiogenesis plays a major role in tumor formation thus chronic inflammation and angiogenesis play synergetic effect in cancer. So Blockade of this combination results in the reduction of a tumor, in conquest to find a potent inhibitor of inflammatory angiogenesis.

Benzophenone molecules bring us hope in this conquest. Benzophenone molecules are known for their potency against a tumor (Prabhakar et al., 2006) with minimal effect on normal cells. As an approach in designing of the compound, we have conjugated
Diamide to benzophenone and reported "N-(2-\{2-[4-(4-bromobenzoyl)-2-methyl-phenoxy]-acetylamino -phenyl)-2-[2-methyl4-(2-methyl-benzoyl)-phenoxy] acetamide (BT0009K)" (Fig. 1a) has potent antitumor efficacy against multiple cancer cell lines with regression of angiogenesis (Zabiulla et al., 2016). In the current detailed investigation of BT009K has been carried out to infer that it effectively reduces inflammation-induced angiogenesis in both tumorigenic and non-tumorigenic model system.
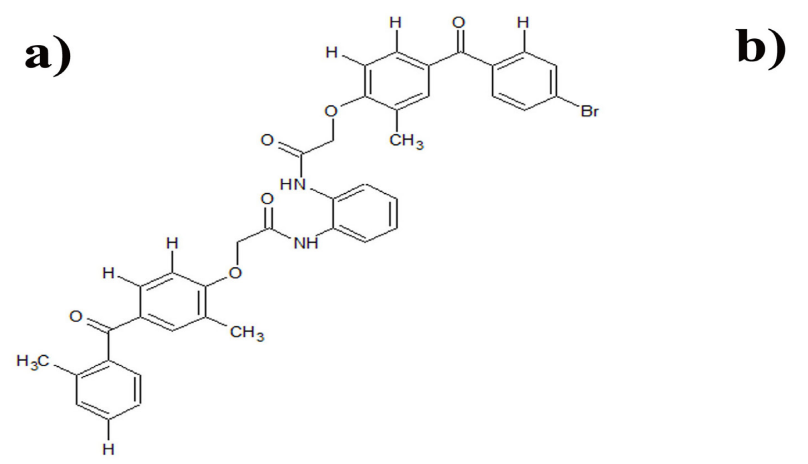

\begin{tabular}{|c|c|c|}
\hline $\begin{array}{c}\text { SI. } \\
\text { No }\end{array}$ & Cell lines & ICs0 \\
\hline 1 & EAC & $\mathbf{3 . 9 \mu M}$ \\
\hline 2 & DLA & $23 \mu \mathrm{M}$ \\
\hline 3 & A549 & $\mathbf{2 4 \mu M}$ \\
\hline 4 & MCF-7 & $\mathbf{2 3 \mu M}$ \\
\hline $\mathbf{5}$ & HUH-7 & $>\mathbf{5 0 \mu M}$ \\
\hline 6 & HepG2 & $>\mathbf{5 0 \mu M}$ \\
\hline 7 & $\mathbf{A 3 7 5}$ & $>\mathbf{5 0 \mu M}$ \\
\hline $\mathbf{8}$ & $\mathbf{B 1 6 F 1 0}$ & $>\mathbf{5 0 \mu M}$ \\
\hline
\end{tabular}

c)

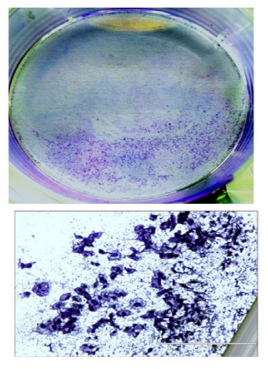

CONTROL
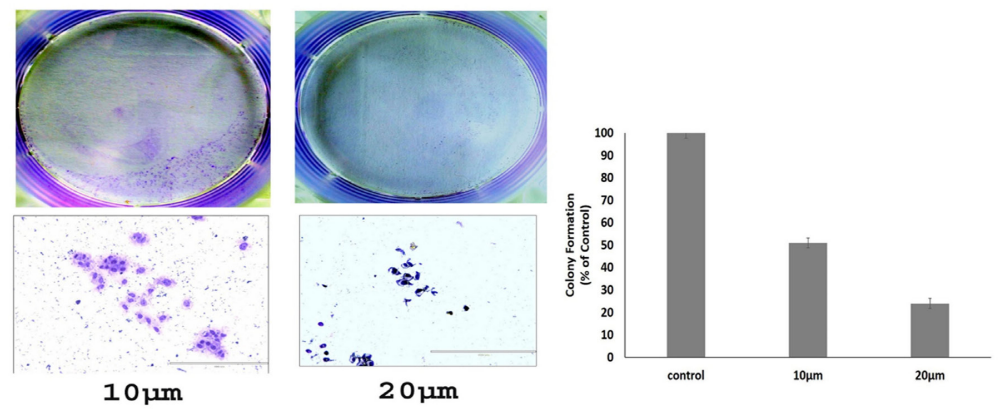

d)

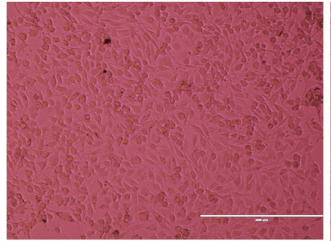

ohr
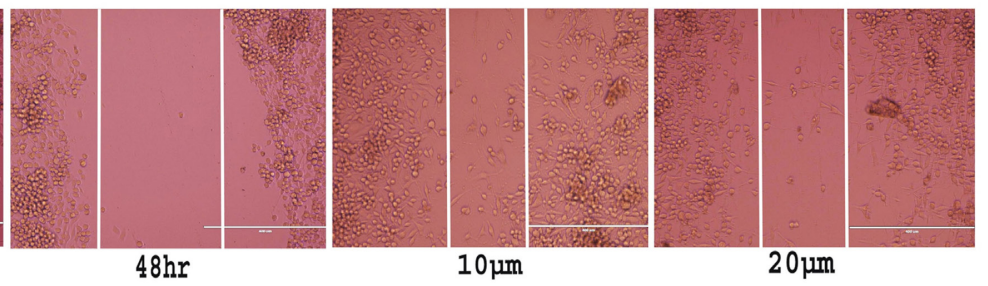

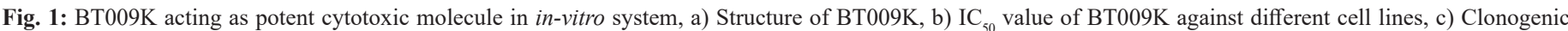

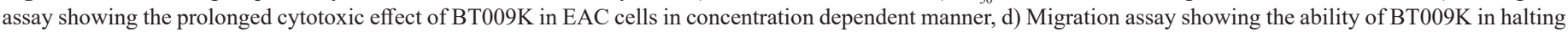
the migration of EAC cells.

\section{MATERIALS AND METHOD}

\section{In-vitro assays}

\section{Cell culture and maintenance}

Ehrlich Ascites-E (EAC), Dalton's Ascites Lymphoma (DLA), Breast adenocarcinoma (MCF-7), Lung adenocarcinoma (A549), Hepatocellular carcinoma (HUH-7, HepG2), human melanoma (A375), mouse melanoma (B16F10)cell lines were procured from NCCS Pune. Cells were cultured using DMEM or RPMI media (Gibco-Invitrogen, USA), with 10\% FBS (Invitrogen,
USA), suitable antibiotics and antimitotic (Sigma Aldrich, USA), in a humidified incubator at $37^{\circ} \mathrm{C}$ with the supply of $5 \% \mathrm{CO} 2$.

\section{Lactate dehydrogenase assay}

The cytotoxic effect of BT009K was assessed through LDH release assay screened against EAC, DLA, Huh-7, Hepg2, B16F10, A375, A549, and MCF-7. Cells were treated with or without BT009K in different concentration $(0,5,10,25,50$, and $100 \mu \mathrm{m}$ ) for $48 \mathrm{hrs}$ of incubation as stated previously (Ranganath et al., 2013). The percentage of $\mathrm{LDH}$ released to the media was directly proportional to the percentage of dead cells. 


\section{Clonogenic assay}

Anti-neoplastic effect of BT009K against EAC cell proliferation in-vitro (Franken et al., 2006) was carried out accordingly. In brief, EAC cells were cultured in eight-well plate in-vitro and exposed with BT009K for 6 hrs and washed with fresh medium. After culturing for 12 days 12 days cells were fixed with methanol and stained with crystal violet and colonies were counted and photographed.

\section{Migration assay}

EAC cells were cultured in-vitro, scratched and treated with or without BT009K for $48 \mathrm{hrs}$. Cells were fixed with methanol, stained in crystal violet and images were photographed at $10 \mathrm{X}$ resolution. Differences in the percentage of cell migration in treated and control were analyzed (Cory, 2011).

\section{Non tumorigenic assays}

\section{Chorioallontoic membrane (CAM) assay}

Anti-angiogenic effect of BT009K was analyzed through rVEGF165 induced in-vivo CAM assay followed by treatment with BT009K within 8 days of fertilized eggs as described earlier (Prabhakar et al., 2006). Changes in the microvessel density (MVD) count was observed and photographed.

\section{Corneal inflammatory angiogenesis assay}

Anti-inflammatory angiogenesis effect of BT009K was assessed through rat corneal inflammatory angiogenesis assay by anesthetizing the animal with ketamine and xylazine. Followed by placing the sterile filter paper discs pre-dipped in $1 \mathrm{M} \mathrm{NaOH}$ (alkaline solution) and placing it on the eye for 30 seconds. The eyes were washed immediately with Phosphate buffer saline for inducing inflammatory angiogenesis. The recombinant VEGF165 was used to enhance the angiogenesis in the cornea in presence or absence of BT009K $(0,10$, and $20 \mu \mathrm{m})$. After 4 days developed MVD was observed in the cornea of the rats and quantified. The cornea was dissected and processed for histological examination for vascular modulation (Prabhu et al., 2017).

\section{Tumorigenic assays}

\section{Animal models and ethics}

Male Swiss albino mice weighing 25-28 g of 35-45 days old were used for this study. Each group consisted of 10 mice caged in polyacrylic cages with a supply of standard food and water. The Institutional animal ethical committee (IAEC) certificate was obtained from SJM College of pharmacy, Chitradurga, India, in accordance with the CPCSEA guidelines for laboratory animal facility (SJMCP/IAEC/07/2015-16).

\section{Tumor models and treatment}

Effect of BT009K in in-vivo tumor model system was checked in EAC ascites model system. In brief, Ehrlich ascites carcinoma cells $\left(5 \times 10^{6}\right.$ cells $)$ were cultured and transplanted into three groups of male Swiss albino mice. Each group consists of $\mathrm{n}=10$ animals. After the development of a tumor, BT009K was treated at two different concentration $50 \mathrm{mg}$ and $75 \mathrm{mg} / \mathrm{kg}$ body weight along with appropriate vehicle control. Treatment was given on every alternate day after tumor establishment. On the last day, (10th day) of tumor growth mice was sacrificed and different tumor parameters like packed cell volume, ascites volume, tumor growth, and survival were assessed (Vijay Avin et al., 2014).

\section{Peritoneal angiogenesis}

The density of Microvessel formation in the peritoneum region of a tumor-bearing mice treated with $\mathrm{BT} 009 \mathrm{~K}(50,75$ mgkg body weight) was assessed as reported earlier (Weidner et al., 1991).

\section{Immunohistochemical (IHC) analysis}

Peritoneum from the control and BT009K treated mice were processed for immunostaining with Anti-CD31 antibody for MVD evaluation along with $\mathrm{H} \& \mathrm{E}$ stained counter slides as reported earlier (Prabhu et al., 2017). The slides were observed in the light microscope and the changes in the intensity of the antibody staining were evaluated.

\section{RESULTS AND DISCUSSION}

\section{BT009K induces cytotoxicity against EAC cells}

Lactate dehydrogenase ( $\mathrm{LDH})$ release assay system is one of the gold standard assays to study the cytotoxic ability of compound where an increase in the LDH enzyme in the media is directly proportional to the number of lysed cells (Chan et al., 2013). BT009K was screened against EAC, DLA, A549, Huh-7, HepG2, MCF-7, A375, and B16F10. Cells were incubated for $48 \mathrm{hrs}$ with BT009K $(0,5,10,25,50$, and $100 \mu \mathrm{m})$. BT009K (Fig. 1a) showed a significant cytotoxic effect against EAC with an IC50 value of $3.9 \mu \mathrm{m}$. But moderate activity was reported against A549 and MCF-7 and DLA cell lines with 24, 23, and 23 um, respectively. No significant activity was observed in Huh-7, Hepg2, A375, and B16F10 cell lines (Fig. 1b) inferring the specificity of BT009K against EAC cells. Each tumor has their own drug response and long-term cytotoxicity of drugs varies for different tumor cells. Each tumor has individual scale against different compounds (Robert, 1991). To check the longterm ability of BT009K on tumor cells, a clonogenic assay was performed which is one of the foremost assay systems to evaluate the colony forming ability. The BT009K induces Longterm cytotoxic effect against EAC cells with the decreased number of colonies inferring the prolonged cytotoxic effect of the compound on EAC cells in a dose-dependent manner. Around $50 \%$ decrease in $10 \mu \mathrm{m}$ concentration and $80 \%$ decrease in $20 \mu \mathrm{m}$ concentration as compared to the untreated cells were noticed (Fig. 1c).

Cell migration is one of the fundamental pathological and physiological process involved during inflammation, cancer and wound healing conditions. During the process of cell migration, different proteins and enzymes like VEGF, MMP2, 9 play a vital role. Migration of tumor cells is the last stage in cancer progression and compound inhibiting the migration of tumor cells is vital for regression of a tumor, Migration assay is the suitable type of assay to assess 
the capability of compounds against tumor cell migration (Hulkower and Herber 2011). The BT009K regressed the migration of tumor cells as observed in migration assay in a concentration-dependent manner compared to the control (Fig. 1d). The result implies BT009K is a potent cytotoxic molecule with anti-invasive behavior.

a)

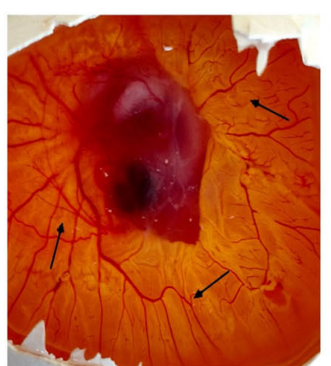

Normal

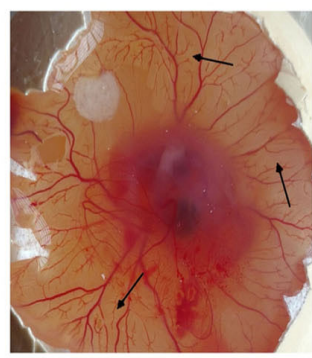

rVEGF $_{165}$

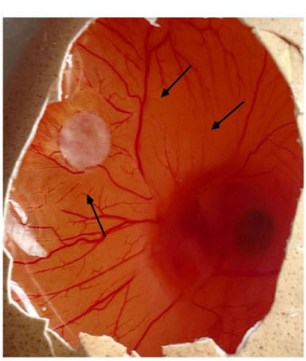

$10 \mu \mathrm{m}$

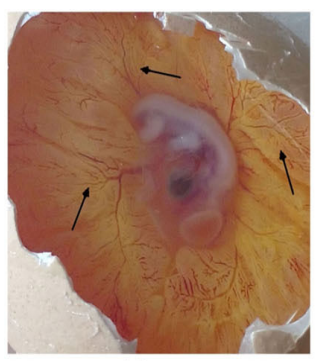

$20 \mu \mathrm{m}$

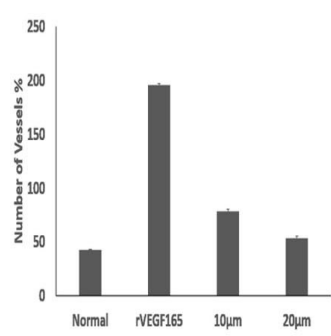

b)
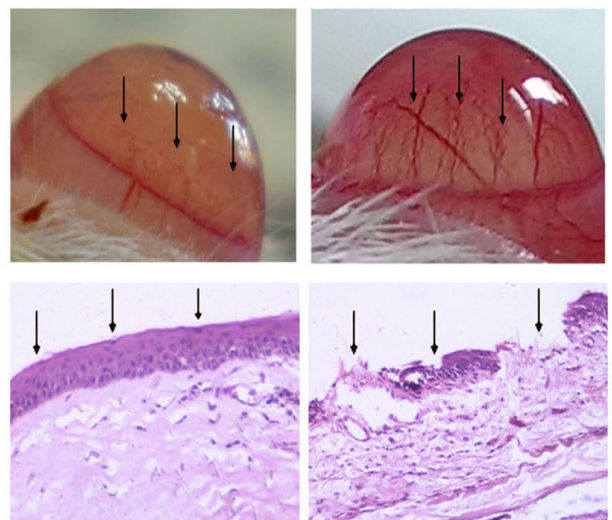

Normal
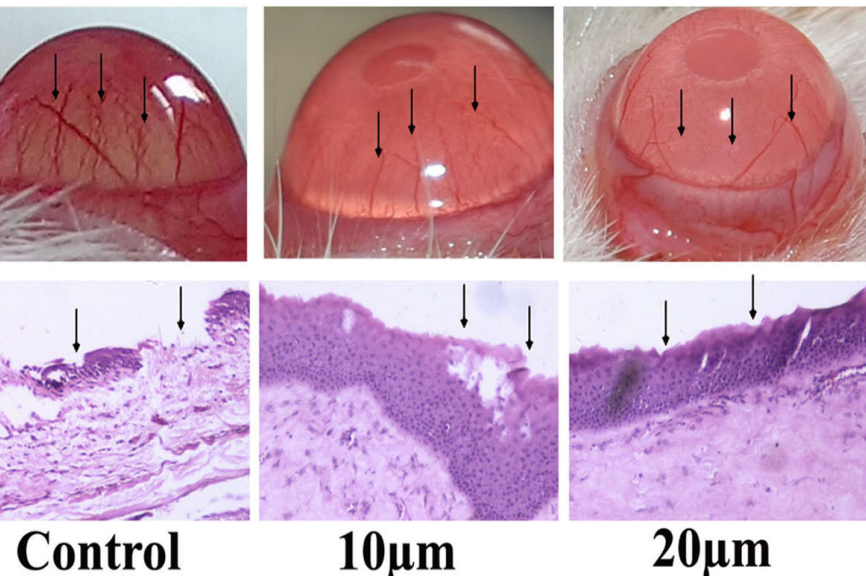

$10 \mu \mathrm{m}$
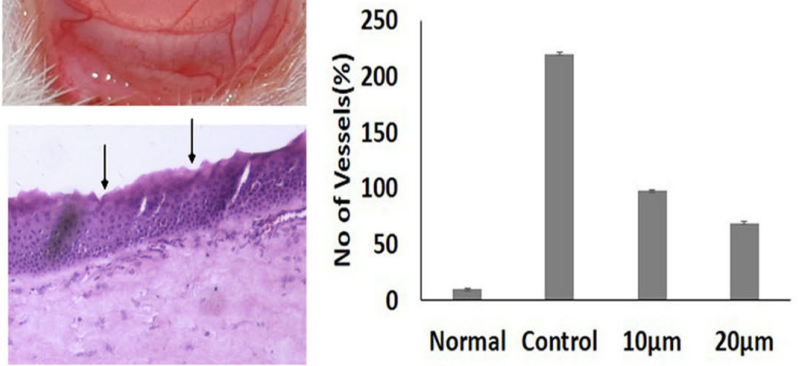

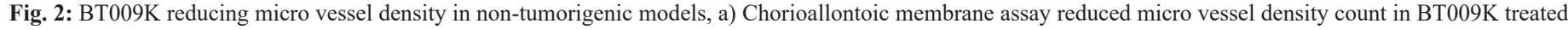

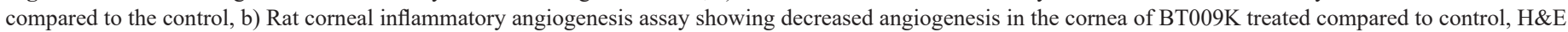
staining showing decreased micro vessel density in BT009K treated.

\section{BT009K antiangiogenic molecule in the non-tumorigenic model system}

Non-tumorigenic models are often used to check the effect of compounds. Chorioallantoic membrane assay is one of the supportive angiogenic assay systems were rVEGF165 induced neovascularisation is formed (Prabhakar et al., 2006). Newly developed vascularisation was reduced in BT009K treated egg CAM compared to the untreated in a dose-dependent manner (Fig. 2a). Further, the effect of BT009K was checked in inflammation-induced angiogenesis model viz Rat corneal angiogenesis. In this model, alkali burn induces local inflammation in the cornea and which causes extensive inflammation of sprouting of a blood vessel (Zhou et al., 2010). The BT009K effectively reduces the MVD in corneal region induced by inflammation in a concentrationdependent manner. About $\sim 50 \%$ decrease in MVD density in $10 \mu \mathrm{m}$ concentration and in $20 \mu \mathrm{m}$ concentration was nearly to the normal (Fig. 2b).

\section{BT009K regresses ascites a tumor in an in-vivo model}

In-vivo ascites tumour model is one of the best model systems to study inflammatory mediated angiogenesis were tumour cells are cultured in the peritoneum region of mice, tumour cells recruit various inflammatory cells and thereby inducing angiogenesis by enhancing the pro-angiogenic signalling molecules and this results in extensive formation of neovascularization and leading to the development of a tumour (Vijay Avin et al., 2014). The in-vivo cytotoxic effect of BT009K was confirmed by in-vivo culturing EAC cells $\left(5 \times 10^{6}\right.$ cells $)$ in the peritoneum region of healthy Swiss albino mice weighing about 25-28 g, after the onset of a tumor in mice BT009K was treated to mice with two different concentrations, i.e., $50 \mathrm{mg}$ and $75 \mathrm{mg} / \mathrm{Kg}$ bwt. Treatment was given for three doses on alternate days and resulted in reduced tumor growth in a dose-dependent manner compared to the untreated (Fig. 3a). The findings were concurrent with other tumor growth parameters like body weight (Fig. 3d), ascites secretion (Fig. 3b) and tumor cell counts (Fig. 
3c). Treatment with BT009K treated also increases with survival time than compared with untreated animals (Fig. 3e).

\section{BT009K reduces neovascularisation in peritoneum region}

The ascites tumor model system helps in generating stroma when tumor cells are implanted in the peritoneum region thereby inducing neovascularization in peritoneum region (Janice et al., 1995). Neovascularisation during cancer condition benefits a tumor by supplying essential nutrients and growth factors for tumor cells, endothelial cells express CD31 as cell surface marker during cancer condition due to extensive vascularisation expression of CD31 is also increased (Weidner et al., 1991). EAC bearing mice are the best reliable model to study neovascularisation in the peritoneum region of mice. The peritoneum of BT009K treated mice showed reduced MVD as seen visibly in the peritoneal lining (Fig. 4a). Further histological examination confirmed the reduced MVD count both H\&E stain (Fig. 4b) as well as CD31 immunostain (Fig. 4c).

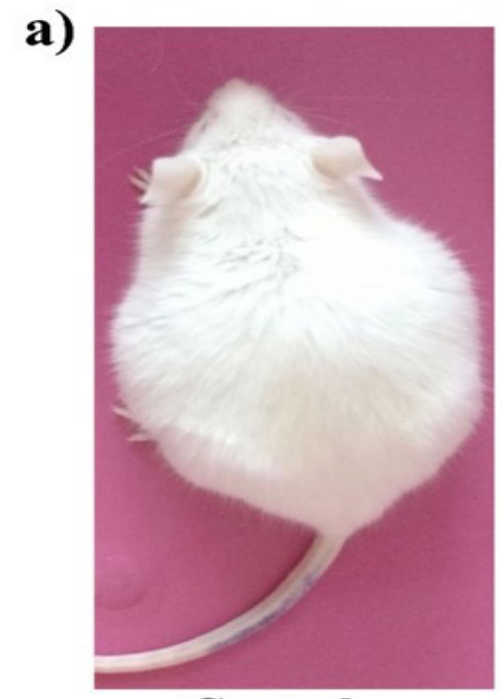

Control

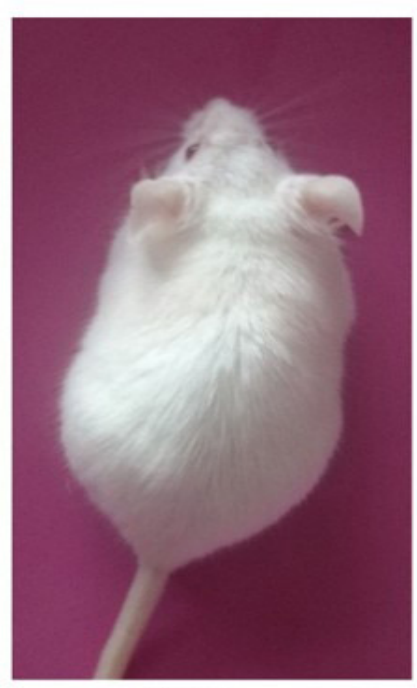

$50 \mathrm{mg}$

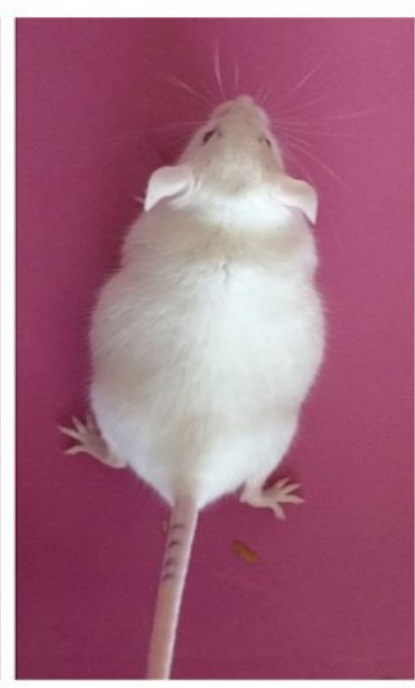

$75 \mathrm{mg}$ b)

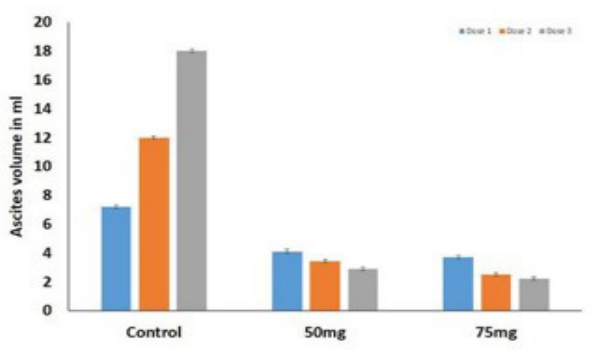

d)

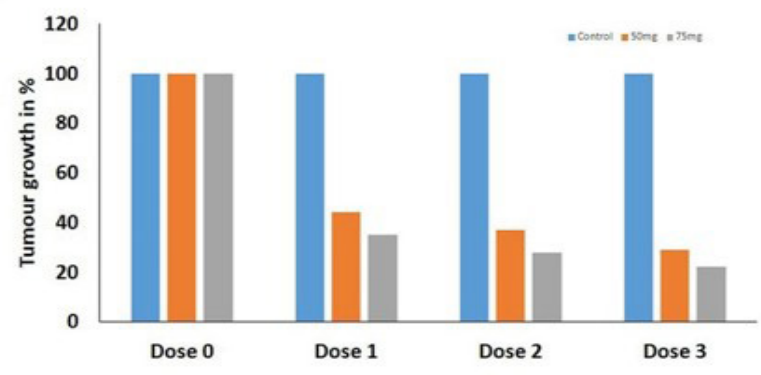

c)

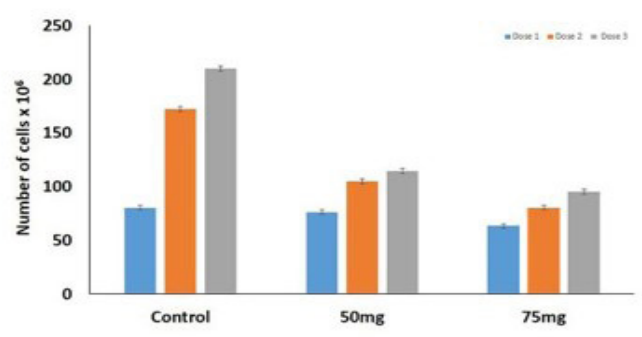

e)

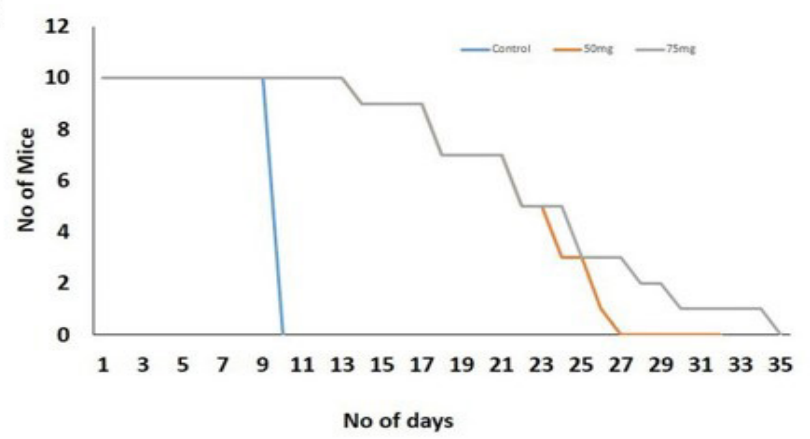

Fig. 3: In-vivo effect of BT009K in EAC ascites tumour model. a) Physical morphology showing decreased body mass in treated compared to the control. b) Decreased ascites volume in treated mice in concentration dependent manner. C) Diminished cell count in BT009K treated mice. d) Reduced tumour growth in BT009K treated mice. e) Graph showing prolonged survivality of BT009K treated mice. 
a) EAC induced peritoneal angiogenesis
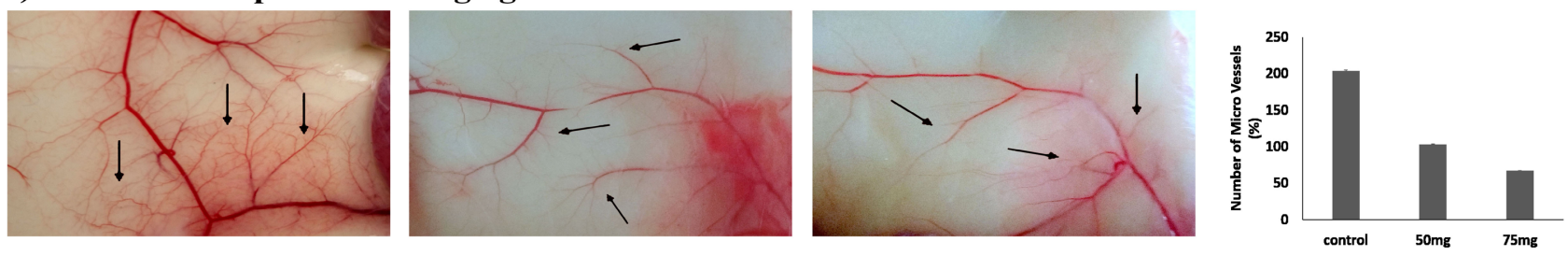

\section{b) H\&E staining of peritoneum}
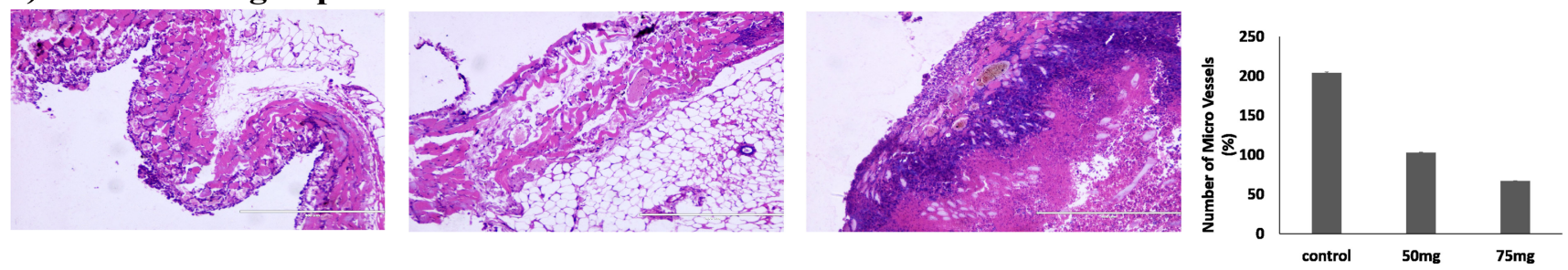

c) Immunohistochemistry of CD31

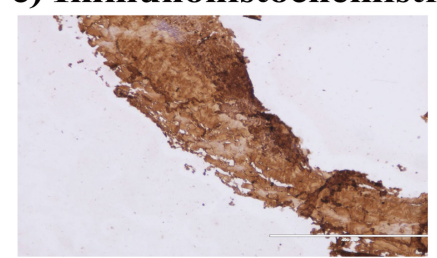

Control

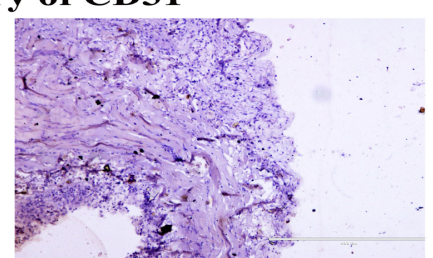

$50 \mathrm{mg} / \mathrm{kg} \mathrm{b.w}$

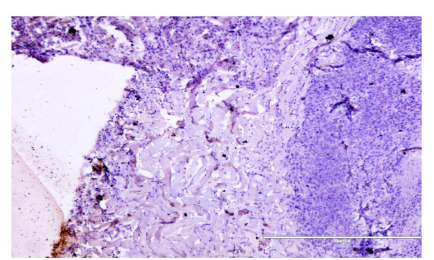

$75 \mathrm{mg} / \mathrm{kg} \mathrm{b.w}$

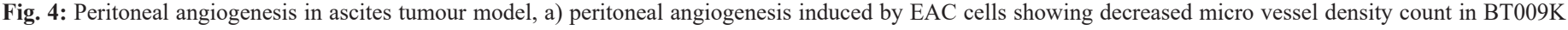

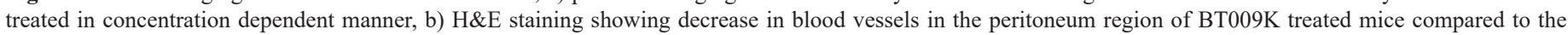
control mice, c) IHC showing the decreased expression of CD31 in peritoneum of BT009K treated mice.

\section{CONCLUSION}

Unregulated inflammation turns from acute stage to chronic stage leading to malignancy. Inflammation and angiogenesis both play a major role in the development of a tumor. Benzophenones are known for highly target specific compounds. As in the path of development target specific drugs, we focused on the coupling of Diamide group to the Benzophenone, which is one of the basic approaches to develop an effective drug, BT009K. The BT009K was screened against multiple cell lines using LDH release assay to evaluate the cytotoxic nature which was found to be more effective in EAC with $3.9 \mu \mathrm{M}$ than any other cell lines along with prolonged cytotoxic effect. Down the line, BT009K compound implied antiangiogenic effect both in non-tumorigenic and this non-tumorigenic model both in-vitro and in-vivo. Considering the above results BT009K can be further developed as target specific drug in inflammatory angiogenesis disorders.

\section{ACKNOWLEDGMENTS}

Shamanth Neralagundi H.G. acknowledges thankfully for Lady Tata Memorial Trust (LTMT) Mumbai for the JRF award for the year 2015-16.B.T. Prabhakar thankfully acknowledges the financial support provided by B.T. Prabhakar gratefully acknowledges the grant extended by DBT (6242-P37/RGCB/ PMD/DBT/PBKR/2015).

\section{CONFLICT OF INTEREST}

All the authors declare that there are no conflicts of interest.

\section{REFERENCES}

Carmeliet P. Angiogenesis in life, disease and medicine. Nature, 2005; 438:932-936.

Cory G. Scratch-wound assay. Methods Mol Biol, 2011; 769: $25-30$. 420: $860-7$

Coussens LM, Werb Z. Inflammation and cancer. Nature, 2002;

Chan FK, Moriwaki K, De Rosa MJ. Detection of Necrosis by Release of Lactate Dehydrogenase (LDH) Activity. Methods Mol Biol, 2013; 979: 65-70.

Eran E, Roni N, Christoph AT, Bo Hu, Chengcheng J and Richard AF. Inflammation-induced cancer: crosstalk between tumours, immune cells and microorganisms Nature reviews/ cancer, 2013; 13: 759-771.

Franken NA, Rodermond HM, Stap J, Haveman J, Van Bree C. Clonogenic assay of cells in vitro. Nat Protocol, 2006; (5): 2315-2319.

Hanahan D, Weinberg RA. The hallmarks of cancer. Cell, 2000; 100: $57-70$.

Hulkower KI, Herber RL. Cell Migration and Invasion Assays as Tools for Drug Discovery. Pharmaceutics, 2011; 3: 107-124.

Janice AN, Ellen SM, Kemp TH, Eleanor JM, Ann MD, and Harold FD. Pathogenesis of Ascites Tumour Growth: Angiogenesis, Vascular remodeling, and Stroma Formation in the Peritoneal Lining. Cancer research, 1995; 55: 376-385.

Kinzler KW, Vogelstein B. Lessons from hereditary colorectal cancer. Cell, 1996; 87:159-70.

Khanum SA1, Shashikanth S, Deepak AV. Synthesis and antiinflammatory activity of benzophenone analogues, Bioorg Chem, 2004; 32(4): 211-222.

Nathan C. Points of control in inflammation. Nature, 2002; 420: 
Philip M, Rowley DA, Schreiber H. Inflammation as a tumor promoter in cancer induction. Semin Cancer Biol, 2004; 14: 433-9.

Prabhu Thirusangu, Vigneshwaran V, Vijay Avin BR, Rakesh H, Vikas HM, Prabhakar BT. Scutellarein antagonizes the tumorigenesis by modulating cytokine VEGF mediated neoangiogenesis and DFF-40 actuated nucleosomal degradation; bbrc, 2017; 0006-291.

Prabhakar BT, Khanum SA, Jayashree K, Salimath BP, Shashikanth S. Antitumor and proapoptotic effect of novel synthetic benzophenone analogs in Ehrlich ascites tumour cells, Bioorg. Med. Chem. Lett, 2006; 14: 435-446.

Robert MH. In Vitro Sensitivity Assays in Cancer: A Review, Analysis, and Prognosis; Journal of Clinical Laboratory Analysis, 1991; 5: $133-143$

Ranganath VL, Avin BR., Thirusangu P, Prashanth T, Prabhakar BT, Khanum SA. Life Sci, 2013; 93: 904-911.

Virchow, R. An address on the value of pathological experiments. Br. Med. J. 1881; 2: 198-203.

Vijay Avin BR, Thirusangu P, Ranganatha VL, Firdouse A, Prabhakar BT, Khanum SA. Synthesis and tumour inhibitory activity of novel coumarin analogs targeting angiogenesis and apoptosis, Eur. J. Med. Chem, 2014; 75: 211-221.
Weidner N, Semple JP, Welch WR, Folkman J. Tumor angiogenesis and metastasis-correlation in invasive breast carcinoma $\mathrm{N}$. Engl, J. Med, 1991; 324: 1-8.

Zhou SY, Xie ZL, Xiao O, Yang XR, Heng BC, Sato Y. Inhibition of mouse alkali burn induced-corneal neovascularization by recombinant adenovirus encoding human vasohibin-1; Molecular Vision, 2010; 16: 1389-1398.

Zabiulla, Shamanth Neralagundi HG, Bushra Begum, Prabhakar BT, Shaukath Ara Khanum. Design and synthesis of diamide-coupled benzophenones as potential anticancer agents European Journal of Medicinal Chemistry, 2016; 115: 342-351.

How to cite this article:

Shamanth Neralagundi HG, Zabiulla, Khanum SA, Manjunatha H, Prabhakar BT. Antitumor Hybrid BT009K Modulates Inflammation Induced Neovascuaralization in Both Tumorigenic and Non-Tumorigenic Model System. J App Pharm Sci, 2018; 8(04): 143-149. 